\title{
COMPARISON OF $\gamma^{\prime} / \gamma^{\prime \prime}$ PRECIPITATES AND MECHANICAL
}

\section{PROPERTIES IN MODIFIED 718 ALLOYS}

\author{
Encai Guo, Fengqin $\mathrm{Xu}$ and E.A. Loria \\ Central Iron and Steel Research Institute \\ Beijing, China \\ and \\ Niobium Products Company \\ Pittsburgh, PA, USA
}

\begin{abstract}
Microstructural instability and loss in strength of Alloy 718 at and above $650^{\circ} \mathrm{C}$ is caused by the dissolution of the precipitation strengthening $\gamma$ " phase and the formation of the brittle and crack-like $\delta$ phase. Two improved compositional modifications of Alloy 718 were given heat treatments that could change the morphology of the coexisting $\gamma^{\prime} / \gamma^{\prime \prime}$ precipitates. A conventional non-compact $\gamma^{\prime} / \gamma^{\prime \prime}$ structure was obtained in one alloy and a compact $\gamma^{\prime} / \gamma^{\prime \prime}$ structure in the other alloy. A third alloy specifically designed to produce the compact $\gamma^{\prime} / \gamma^{\prime \prime}$ cuboidal precipitate was included for comparison purposes. Higher tensile strength averaging $105 \mathrm{MPa}(2.3 \mathrm{ksi})$ between 400 and $700^{\circ} \mathrm{C}\left(750\right.$ and $\left.1300^{\circ} \mathrm{F}\right)$ and almost three times longer rupture life at $650^{\circ} \mathrm{C}\left(1200^{\circ} \mathrm{F}\right)$ under a stress of $686 \mathrm{MPa}$ (99.5 ksi) were obtained with the non-compact $\gamma^{\prime} / \gamma^{\prime \prime}$ precipitate compared to the compact $\gamma^{\prime} / \gamma^{\prime \prime}$ precipitates and the non compact $\gamma^{\prime} / \gamma^{\prime \prime}$ structure of conventional heat treated 718. Also obtained were significant improvements in tensile yield strength and stress rupture life at 483 to $724 \mathrm{MPa}(70$ to $105 \mathrm{ksi})$ in the 650 to $730^{\circ} \mathrm{C}$ $\left(1350^{\circ} \mathrm{F}\right)$ temperature regime corresponding to $\gamma^{\prime \prime}$ instability in conventional 718 . For this particular high stress range, a $100 \mathrm{hr}$ rupture life at 25 to $40^{\circ} \mathrm{F}$ higher temperature was calculated for the modified alloy with the non-compact $\gamma^{\prime} / \gamma^{\prime \prime}$ structure compared to the trendline established for today"s high-quality 718. For this particular composition, the mechanical properties were apparently optimized by the size and spacing of the non-compact $\gamma^{\prime} / \gamma^{\prime \prime}$ precipitates being more effective in impeding the motion of dislocations through the lattice. There was an increase in the primary strengthening $\gamma^{\prime \prime}$ phase, and the matrix and $\gamma^{\prime}+\gamma^{\prime \prime}$ phases were strengthened by a tungsten addition to this alloy. Also, the grain boundary was strengthened by a small chain of $\mathrm{M}_{6} \mathrm{C}$ phase which inhibited long range grain boundary sliding during stress rupture testing.

Superalloys 718, 625 and Various Derivatives Edited by Edward A. Loria

The Minerals, Metals \& Materials Society, 1991
\end{abstract}




\section{Introduction}

The goal of our study ${ }^{1}$ has been to identify the alloying parameters that determine the strengthening precipitation phases in Alloy 718 and thereby increase the maximum operating temperature. This appears possible through minor changes in alloy composition and heat treatment. 2,3 Our introductory paper $^{4}$ revealed the results of different heat treatments than the conventional 718 heat treatment for two promising compositional modifications of 718 from our initial investigation ${ }^{1}$ which showed superior properties when given the standard 718 heat treatment. The selected heat treatments produced a conventional noncompact mixture of $\gamma^{\prime} / \gamma^{\prime \prime}$ particles in one alloy and a compact $\gamma^{\prime} / \gamma^{\prime \prime}$ precipitate structure in the other alloy. For comparison purposes, Pineau's preferred composition 5 that produces the compact $\gamma^{\prime} / \gamma^{\prime \prime}$ cuboidal precipitate morphology with the appropriate heat treatment was included because it has been reported to provide better thermal stability above $650^{\circ} \mathrm{C}$. Our aim was to evaluate the effect of these heat treatments on precipitate structure and mechanical properties. Particular emphasis was placed on the 650 to $730^{\circ} \mathrm{C}$ temperature regime corresponding to $\gamma^{\prime \prime}$ instability in conventional 718 .

\section{Materials and Procedure}

The modifications of Alloy 718 were vacuum induction melted and cast as 23 $\mathrm{kg}$ ingots in the case of Alloys 5 and 7 and $5 \mathrm{~kg}$ ingot in the case of Alloy 3 . After homogenizing for 24 hours at $1100^{\circ} \mathrm{C}$ and for 1 hour at $1160^{\circ} \mathrm{C}$ to minimize segregation effects, the ingots were hot forged into $32 \mathrm{~mm}$ bars. Specimens cut from the bars provided the compositions listed in Table I. As selected from the introductory paper, ${ }^{4}$ Alloy 5 was solution treated at $1030^{\circ} \mathrm{C}$ for $1 \mathrm{hr}$, air cool, $800^{\circ} \mathrm{C}$

\begin{tabular}{|c|c|c|c|c|c|c|c|c|c|}
\hline & \multicolumn{2}{|c|}{ Table I } & Chemical & \multicolumn{4}{|c|}{ Composition of Alloys } & \multirow{2}{*}{$\frac{w t \cdot g}{B}$} \\
\hline A110y & $C$ & $\mathrm{Cr}$ & Mo & $\mathrm{Ti}$ & $\mathrm{Al}$ & $\mathrm{Nb}$ & $\mathrm{Fe}$ & $W$ & \\
\hline 3 & 0.056 & 17.58 & 2.85 & 0.91 & 0.86 & 5.51 & $1 / .00$ & & 0.0033 \\
\hline 5 & 0.048 & 16.60 & 3.09 & 0.98 & 0.93 & 5.57 & 13.71 & 2.30 & 0.0019 \\
\hline 7 & 0.059 & 17.20 & 2.98 & 1.20 & 1.19 & 4.95 & 19.23 & & 0.0041 \\
\hline Alloy & $\mathrm{Ti}$ & A1 & \multicolumn{2}{|c|}{$\mathrm{Nb}$} & $\mathrm{A} 1+\mathrm{T} i+\mathrm{Nb}$ & \multicolumn{2}{|c|}{$\mathrm{A} I / \mathrm{Ti}$} & $\mathrm{A} 1+\mathrm{Ti} / \mathrm{Nb}$ & at. 8 \\
\hline 3 & 1.18 & 1.85 & \multicolumn{2}{|c|}{3.44} & 6.47 & \multicolumn{2}{|c|}{1.57} & 0.88 & \\
\hline 5 & 1.21 & 2.04 & \multirow{2}{*}{\multicolumn{2}{|c|}{$\begin{array}{l}3.55 \\
3.16\end{array}$}} & 6.80 & \multicolumn{2}{|c|}{1.69} & 0.92 & \\
\hline 7 & 1.48 & 2.33 & & & 6.97 & \multicolumn{2}{|c|}{1.57} & 1.21 & \\
\hline
\end{tabular}

for $1.5 \mathrm{hr}$, then furnace cool $\left(50^{\circ} \mathrm{C} / \mathrm{hr}\right)$ to $650^{\circ} \mathrm{C}$, hold for $16 \mathrm{hr}$ and air cool. Alloy 7 and Alloy 3 were solution treated at $980^{\circ} \mathrm{C}$ for $1 \mathrm{hr}$, air cool, $850^{\circ} \mathrm{C}$ for $1 \mathrm{hr}$, then furnace cool $\left(50^{\circ} \mathrm{C} / \mathrm{hr}\right)$ to $650^{\circ} \mathrm{C}$, hold for $16 \mathrm{hr}$ and air cool. These heat treatments produced a $\gamma$ matrix grain size of ASTM5-6 in Alloys 5 and 3 and ASTM6-7 in Alloy 7 . The metallography, tensile, impact and stress rupture testing was done on the heat treated bar stock following the standard procedure in each case.

\section{Results}

Transmission electron micrographs, per Figure 1, revealed that the heat treatment on Alloy 5 produced a conventional mixture of thin disk-shaped $\gamma^{\prime \prime}$ and small round $\gamma^{\prime}$ particles, with a significant number of the $\gamma^{\prime \prime}$ bound to $\gamma^{\prime}$ particles. 

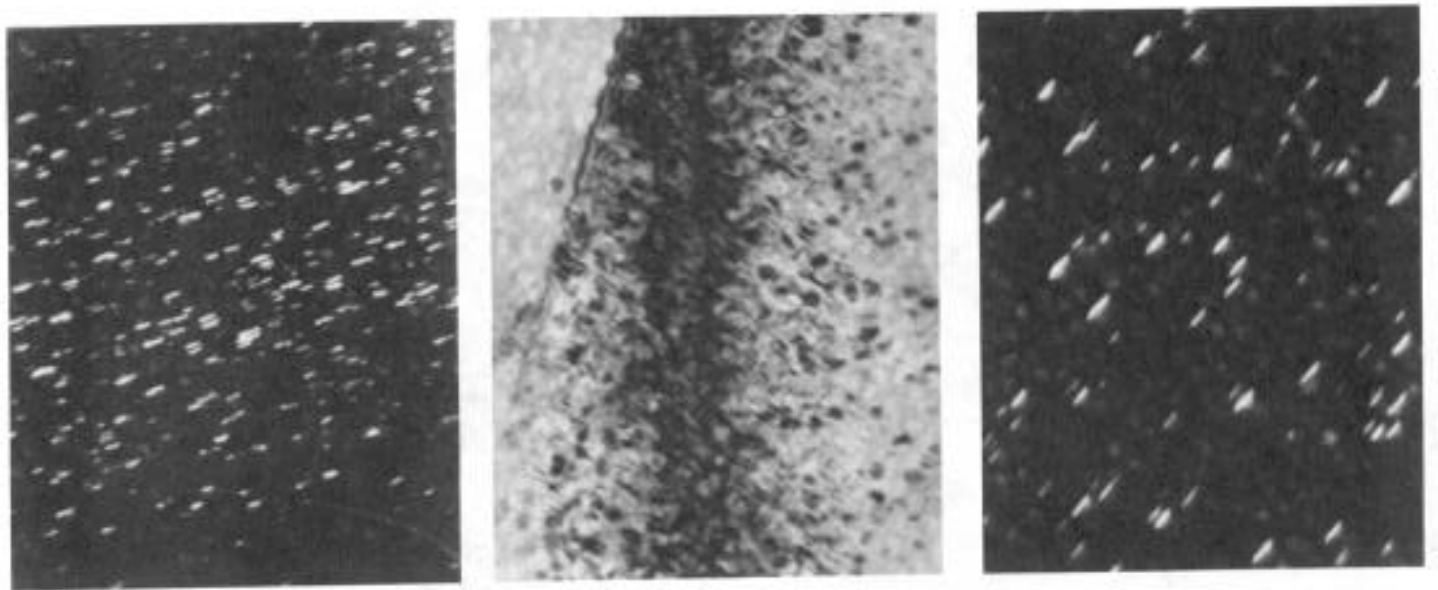

Figure 1. Transmission electronmicrographs of Alloy 5 after specified heat treatment. (a) Dark field, X80000. (b) Bright field, X80000. (c) Dark field, X115000.
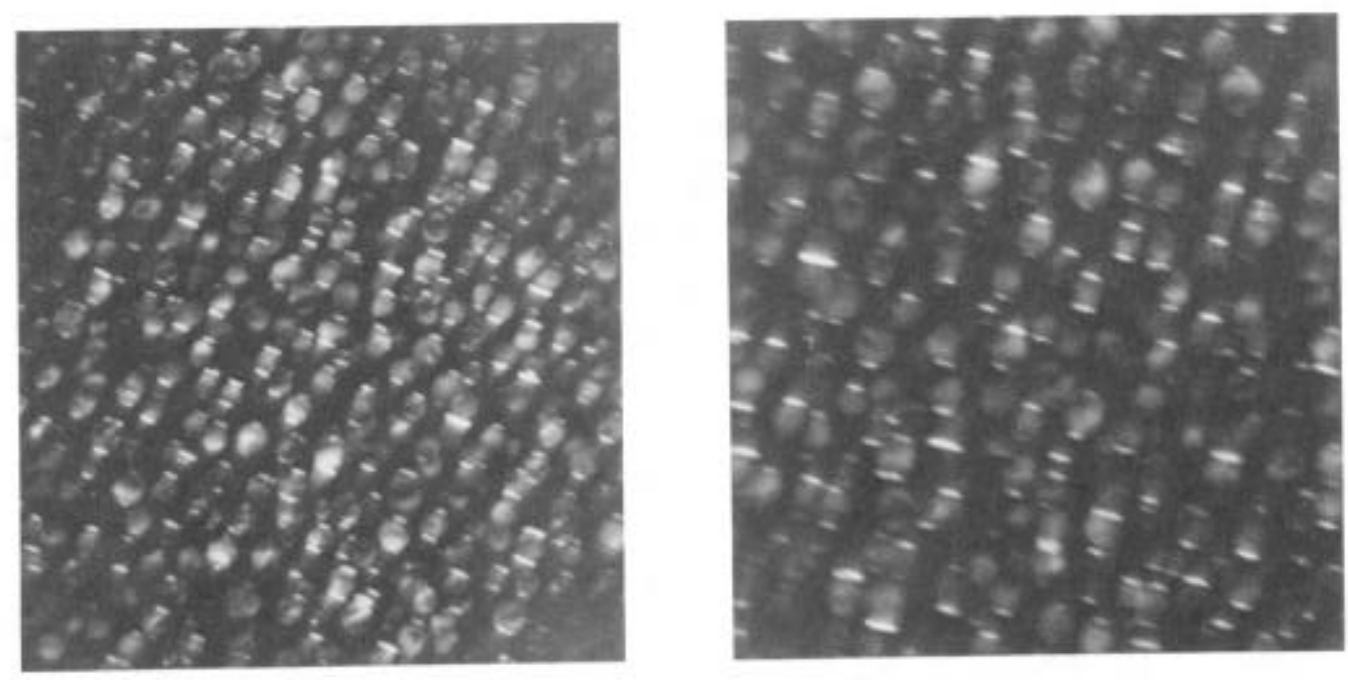

Figure 2. Transmission electronmicrographs of Alloy 7 after specified heat treatment. (a) Dark field, X80000. (b) Dark field, X105000.

Basically, it was not the $\gamma^{\prime} / \gamma^{\prime \prime}$ compact precipitate morphology. The $\gamma^{\prime \prime}$ particles were thinner and spaced closer together than observed in Alloys 3 and 7. The $\gamma^{\prime}$ diameter was about $0.018 \mu \mathrm{m}$ and the $\gamma^{\prime \prime}$ length about $0.025 \mu \mathrm{m}$ in Alloy 5 . There was some evidence of $\mathrm{M}_{6} \mathrm{C}$ phase distributed as a small chain in part of a grain boundary but no needle $\delta$ phase was observed in the grain boundaries or within the grains. The heat treatment employed on Alloy 7 produced the distinctive compact $\gamma^{\prime} / \gamma^{\prime \prime}$ precipitate morphology shown in Figure 2. The $\gamma^{\prime}$ diameter was about $0.033 \mu \mathrm{m}$ and the $\gamma^{\prime \prime}$ length was about $0.023 \mu \mathrm{m}$. A very small amount of $\delta$ phase was observed in the grain boundary but none was seen intragrain. The heat 

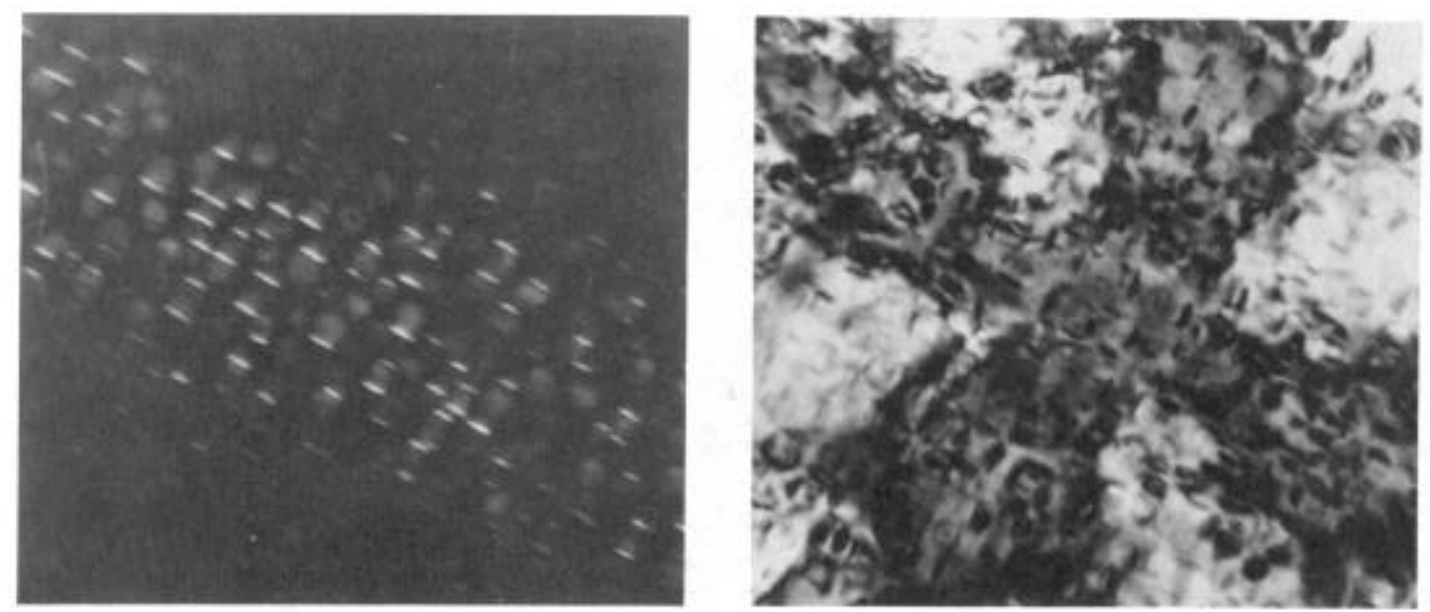

Figure 3. Transmission electronmicrographs of Alloy 3 after specified heat treatment. (a) Dark field, X80000. (b) Bright field, X80000.

treatment employed on Alloy 3 also produced the compact $\gamma^{\prime} / \gamma^{\prime \prime}$ precipitate shown in Figure 3. The $\gamma^{\prime}$ diameter and $\gamma^{\prime \prime}$ length both measured $0.038 \mu \mathrm{m}$ and the distribution of $\delta$ phase in Alloy 3 was similar to Alloy 7 . Generally, for the best creep strength, $\gamma^{\prime}$ particles should be very small but of an optimum size to achieve a good combination of strength and ductility. In this regard, the $\gamma^{\prime}$ particles in Alloy 5 are 50 pct smaller than the $\gamma^{\prime}$ particles in Alloys 7 and 3 .

Chemical analyses of the extraction phases from Alloys 5 and 7 are listed in Table II. In addition, Alloy 5 has 0.58 wt.pct $(\mathrm{NbC}+\mathrm{TiC})$ and Alloy 7 has 0.42 wt.pct $(\mathrm{NbC}+\mathrm{TiC})$. The analytical results reveal no obvious difference in the total amount of $\gamma^{\prime}+\gamma^{\prime \prime}$ extracted from each material. The amounts of Ti and Al which

\begin{tabular}{cccccccccc}
\multicolumn{2}{c}{ Table II } & \multicolumn{6}{c}{ Chemical Analyses of Extracted $\gamma^{\prime}+\gamma^{\prime \prime}$ Phases } \\
\hline Alloy & Ti & Fe & Mo & Cr & Ni & W & Nb & Al & Total \\
\hline 5 & 0.81 & 0.33 & 0.12 & 0.32 & 14.25 & 0.62 & 3.45 & 0.78 & 20.68 \\
7 & 0.99 & 0.40 & 0.05 & 0.24 & 15.67 & & 2.25 & 0.87 & 21.47 \\
\hline
\end{tabular}

are the main elements forming $\gamma^{\prime}$ phase are higher in Alloy 7 which agrees with the large cube-shaped $\gamma^{\prime}$ particles observed in the transmission electron micrographs. Also, the calculated ratio of the volume fraction of $\gamma^{\prime}$ over volume fraction of $\gamma^{\prime \prime}$ phase from dark field TEMs is roughly about 4 for Alloy 7 compared to about 2 for Alloy 5. Conversely, the amount of $\gamma$ " phase, which is the primary strengthening phase in 718 type compositions, is obviously higher in Alloy 5. Strictly on the basis of the compositional ratio of $\mathrm{Nb} /(\mathrm{Al}+\mathrm{Ti}+\mathrm{Nb})$ in at.pct, the values are $52.2 \mathrm{pct}$ for Alloy 5 and 45.3 pct in Alloy 7. Finally, in Alloy 5 , the $\gamma^{\prime}+\gamma^{\prime \prime}$ is strengthened by the 0.62 wt.pct $\mathrm{W}$ which is about 30 wt.pct of the added amount (plus 0.12 wt.pct Mo vs. 0.05 wt.pct Mo in Alloy 7) with the remainder providing solution strengthening of the $\gamma$ matrix.

The mechanical properties of the three alloys are listed in Tables III to V. 
Table III Mechanical Properties of Alloy 5 after Specified Heat Treatment

\begin{tabular}{|c|c|c|c|c|c|c|c|c|c|c|c|c|}
\hline \multicolumn{7}{|c|}{ Tensile Test Results } & \multicolumn{3}{|c|}{ Stress Ruptur } & \multicolumn{3}{|c|}{ Test Results } \\
\hline Temp & 0.28 & Yield & U1t: & nate & El & $\mathrm{RA}$ & Temp & St & ess & Time & E1. & RA \\
\hline${ }^{\circ} \mathrm{C}$ & $\mathrm{MPa}$ & $k s i$ & $\mathrm{MPa}$ & $k s i$ & 8 & $z$ & ${ }^{\circ} \mathrm{C}$ & $\mathrm{MPa}$ & $k s i$ & $\mathrm{hr}$ & $q$ & 운 \\
\hline 25 & 1120 & 162 & 1460 & 212 & 21.0 & 33.7 & 650 & 686 & 99.5 & 273.2 & 10.5 & 25.4 \\
\hline 25 & 1110 & 161 & 1485 & 215 & 22.3 & 36.6 & 650 & 686 & 99.5 & 394.0 & 13.5 & 29.7 \\
\hline 400 & 1085 & 156 & 1565 & 227 & 21.5 & 32.5 & 680 & 724 & 105 & 28.0 & 13.4 & 32.4 \\
\hline 400 & 1065 & 154 & 1505 & 218 & 20.2 & 34.7 & 680 & 724 & 105 & 34.9 & 14.2 & 19.7 \\
\hline 650 & 1005 & 146 & 1275 & 185 & 23.1 & 30 & 700 & 638 & 92.5 & 30.4 & 6.4 & $11 . ?$ \\
\hline 650 & 1040 & 151 & 1320 & 191 & 27.5 & 33.3 & 700 & 638 & 92.5 & 52.9 & 10.8 & 19.0 \\
\hline 700 & 925 & 134 & 1140 & 165 & 9.9 & 16.1 & 700 & 638 & 92.5 & 31.8 & 8.2 & 18.3 \\
\hline 730 & 890 & 129 & 1060 & 154 & 11.4 & 9.7 & 730 & 483 & 70 & 63.6 & 13.3 & 33.8 \\
\hline 730 & 900 & 131 & 1055 & 153 & 9.5 & 11.2 & 730 & 483 & 70 & 59.4 & 17.4 & 40.4 \\
\hline
\end{tabular}

Table IV Mechanical Properties of Alloy 7 after Specified Heat Treatment

\begin{tabular}{|c|c|c|c|c|c|c|c|c|c|c|c|c|}
\hline & \multicolumn{6}{|c|}{ Tensile Test Results } & \multicolumn{6}{|c|}{ Stress Rupture Test Results } \\
\hline \multirow{2}{*}{$\begin{array}{l}\text { Temp } \\
{ }^{\circ} \mathrm{C}\end{array}$} & \multirow{2}{*}{$\begin{array}{l}0.28 \\
\mathrm{MPa}\end{array}$} & \multirow{2}{*}{$\begin{array}{c}\text { Yield } \\
\text { ksi. }\end{array}$} & \multicolumn{2}{|c|}{ U1timate } & \multirow{2}{*}{$\begin{array}{l}\text { E1 } \\
\text { g }\end{array}$} & \multirow{2}{*}{$\begin{array}{l}\mathrm{RA} \\
8\end{array}$} & \multirow{2}{*}{$\begin{array}{l}\text { Temp } \\
{ }^{\circ} \mathrm{C}\end{array}$} & \multicolumn{2}{|c|}{ Stress } & \multirow{2}{*}{$\begin{array}{c}\text { Time } \\
\text { hr }\end{array}$} & \multirow{2}{*}{$\begin{array}{r}\text { E1 } \\
8\end{array}$} & \multirow{2}{*}{$\begin{array}{c}\text { RA } \\
q\end{array}$} \\
\hline & & & $\mathrm{MPa}$ & $\mathrm{ksi} i$ & & & & $\mathrm{MPa}$ & $\mathrm{ksi}$ & & & \\
\hline 25 & 1040 & 151 & 1490 & 216 & 19.0 & 34.1 & 650 & 686 & 99.5 & 180.8 & 8.8 & 20.1 \\
\hline 25 & 1045 & 152 & 1505 & 218 & 19.3 & 34.0 & 650 & 686 & 99.5 & 61.1 & 2.9 & 4.0 \\
\hline & & & & & & & 650 & 686 & 99.5 & 180.3 & 12.9 & 20.0 \\
\hline 400 & 1030 & 149 & 1400 & 203 & 16.0 & 31.4 & 680 & 724 & 105 & 11.2 & 7.7 & 10.9 \\
\hline 400 & 995 & 144 & 1375 & 199 & 16.1 & 33.0 & 680 & 724 & 105 & 11.8 & 9.3 & 17.2 \\
\hline 650 & 985 & 143 & 1225 & 178 & 22.4 & 39.5 & 700 & 638 & 92.5 & 16.7 & 15.9 & 26.4 \\
\hline 650 & 980 & 142 & 1220 & 177 & 24.6 & 47.0 & 700 & 638 & 92.5 & 23.1 & 15.2 & 24.7 \\
\hline 700 & 870 & 126 & $10 / b$ & 156 & 13.4 & 15.7 & 700 & 638 & 92.5 & 22.9 & 19.1 & 24.7 \\
\hline 700 & 920 & 133 & 1070 & 155 & 13.6 & 17.6 & 730 & 483 & 70 & 13.1 & 10.7 & 21.9 \\
\hline 730 & 825 & 120 & 940 & 136 & 12.0 & 13.9 & 730 & 483 & 70 & 22.9 & 24.6 & 39.4 \\
\hline 730 & 825 & 120 & 965 & 140 & 11.0 & 16.1 & 730 & 483 & 70 & 26.1 & 10.4 & 18.7 \\
\hline
\end{tabular}

Table V Mechanical Properties of Alloy 3 after Specified Heat Treatment

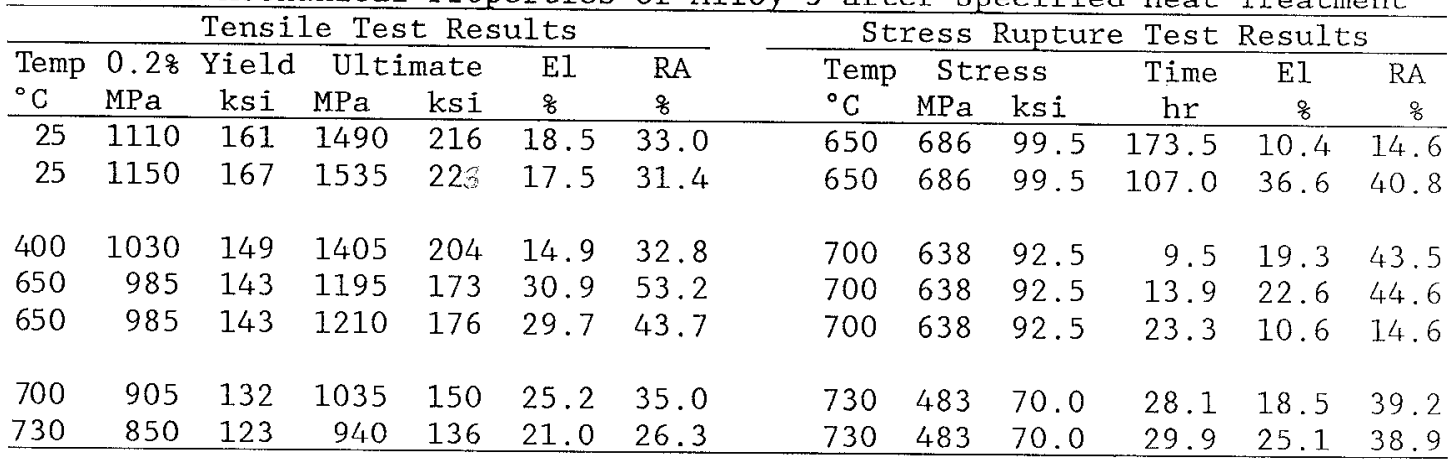




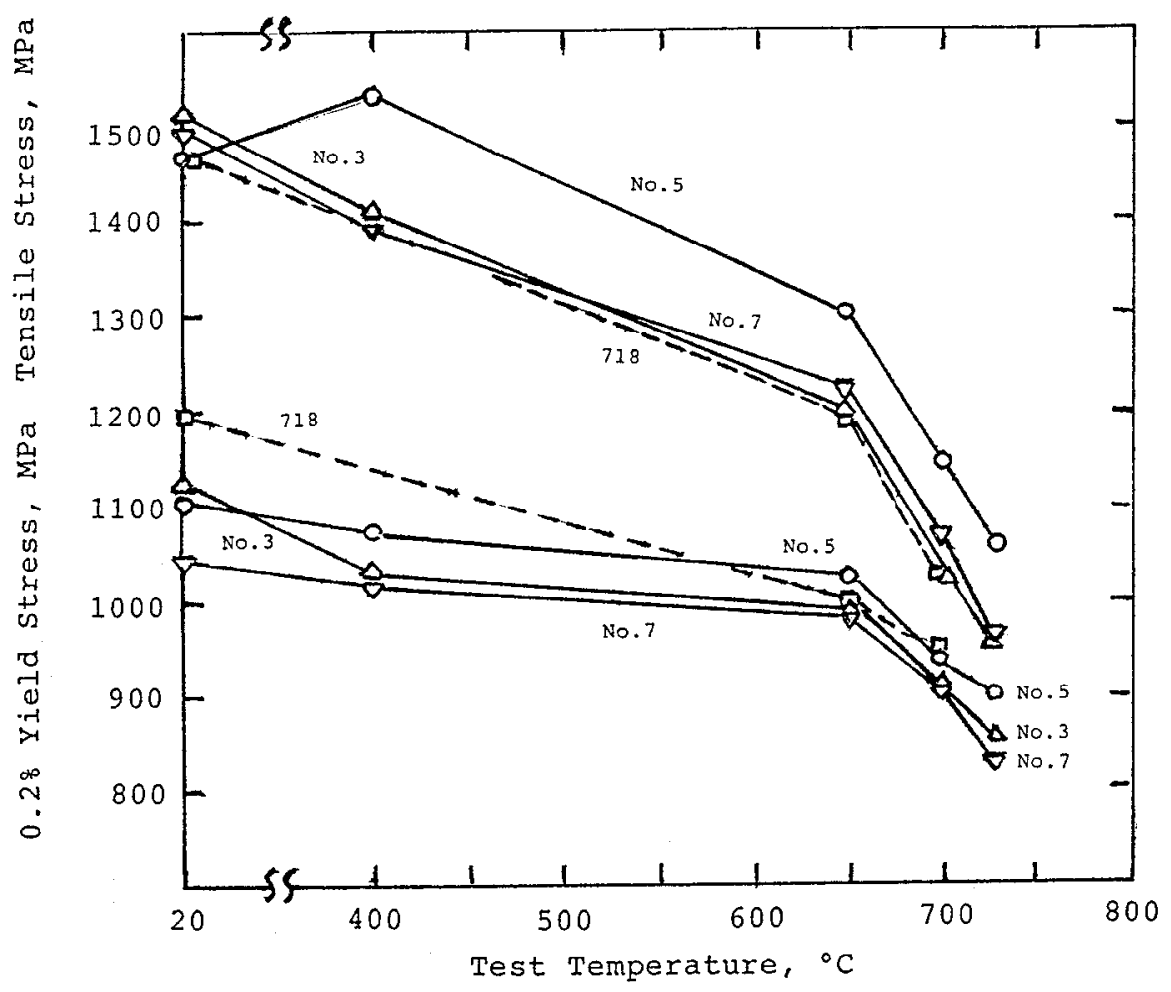

Figure 4. Variation in tensile strength and 0.2 pct yield strength of Alloys 3, 5, 7 and 718 with increasing temperature up to $730^{\circ} \mathrm{C}$.

Depicted graphically in Figure 4, the tensile strengths at room temperature are nearly identical but there is a difference in the yield strength values which are below the value for Alloy 718. However, at test temperatures between $400^{\circ} \mathrm{C}$ and $650^{\circ} \mathrm{C}$, the strength properties of Alloy 5 are significantly higher, and the increase in tensile strength is attributed to the high work hardening rate during plastic deformation. Then, the improvement continues over the expected decline that

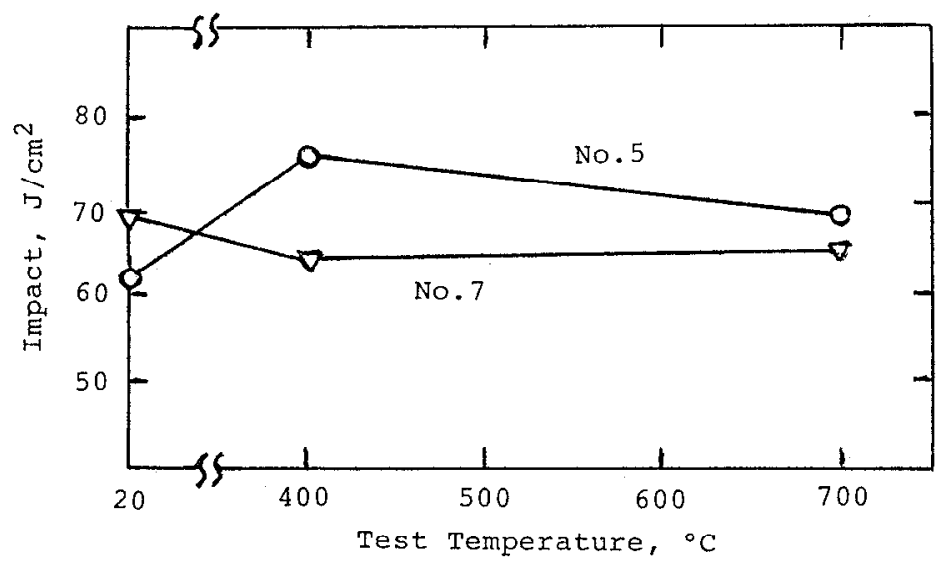

Figure 5. Variation in impact strength of Alloy 5 and Alloy 7 between ambient and $700^{\circ} \mathrm{C}$. 
occurs above $650^{\circ} \mathrm{C}$. A tensile strength of $1140 \mathrm{MPa}(165.3 \mathrm{ksi})$ and yield strength of $925 \mathrm{MPa}(134.2 \mathrm{ksi})$ at $700^{\circ} \mathrm{C}$ and $1058 \mathrm{MPa}(153.1 \mathrm{ksi})$ and $897 \mathrm{MPa}(130.1 \mathrm{ksi})$ at $730^{\circ} \mathrm{C}$ for Alloy 5 are noteworthy. On the other hand, the values for Alloys 7 and 3 are significantly lower and nearly identical throughout the temperature range and closely similar to Alloy 718 up to $700^{\circ} \mathrm{C}$. As seen in Tables III to V, the corresponding elongation values are clustered around 20 pct at room temperature and increase generally at $650^{\circ} \mathrm{C}$ but then decrease in a range of 10 to $16 \mathrm{pct}$ at $730^{\circ} \mathrm{C}$. Reduction of area follows a similar trend and both are considered satisfactory.

From a large number of low cycle fatigue and fatigue crack propagation experiments on Alloy 718, $\mathrm{Xie}^{6}$ has concluded that LCF decreases with increasing temperature mainly because of the decrease in tensile strength and ductility. On this basis, the fact that Alloy 5 produced superior tensile strength and ductility would indicate that LCF life would be improved. Finally, Figure 5 shows the impact test results between ambient and $700^{\circ} \mathrm{C}$ and the higher values obtained on Alloy 5 compared to Alloy 7.

Stress rupture data are recorded in Tables III to $\mathrm{V}$ and the average life of each alloy at temperatures between $650^{\circ} \mathrm{C}$ and $730^{\circ} \mathrm{C}$ is compared in the bar graphs of Figure 6. At the present peak temperature of $650^{\circ} \mathrm{C}$ for today's 718 under a stress of $686 \mathrm{MPa}(99.5 \mathrm{ksi})$, Alloy 5 lasts an average of $348 \mathrm{hr}$ which is three times the $116 \mathrm{hr}$ life obtained on Alloy 718. Practically the same degree of improvement occurs over Alloys 7 and 3 which had the same rupture life of $140 \mathrm{hr}$. Also, the superiority of Alloy 5 continues in the other three comparisons. At $700^{\circ} \mathrm{C}$ under a stress

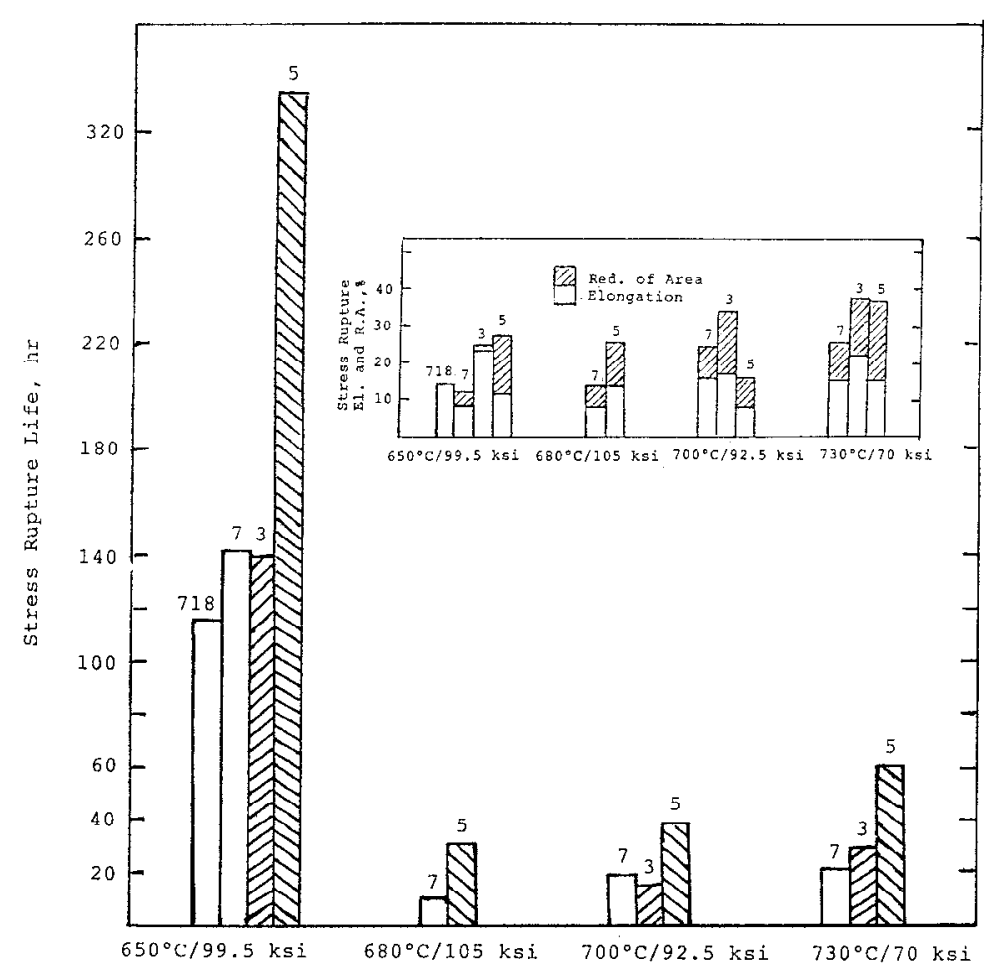

Figure 6. Comparison of stress rupture times obtained on Alloys 3, 5, and 7 for the specified temperatures and stresses, and the respective elongation and reduction of area values. 
of $638 \mathrm{MPa}(92.5 \mathrm{ksi})$ and at $730^{\circ} \mathrm{C}$ under a stress of $483 \mathrm{MPa}(70 \mathrm{ksi})$, Alloy $5 \mathrm{had}$ two or three times the rupture life of Alloys 7 and 3. The corresponding elongation and reduction of area values were satisfactory in all cases and revealed no embrittlement tendency over the 650 to $730^{\circ} \mathrm{C}$ range. The,phase stability of Alloy 5 is confirmed by these results of long survival at these high temperatures and stresses whereas conventional Alloy 718 inherently suffers significant deterioration in properties under these test conditions.

In examining the microstructures of specimens after stress rupture testing (and also impact testing), it was recognized that there would be internal stresses, dislocations and slip bands in the TEM foils. The very close spacing of the thin $\gamma^{\prime \prime}$ plates continued in Alloy 5, per Figure 7, after it ruptured in 394 hours at $650^{\circ} \mathrm{C}$
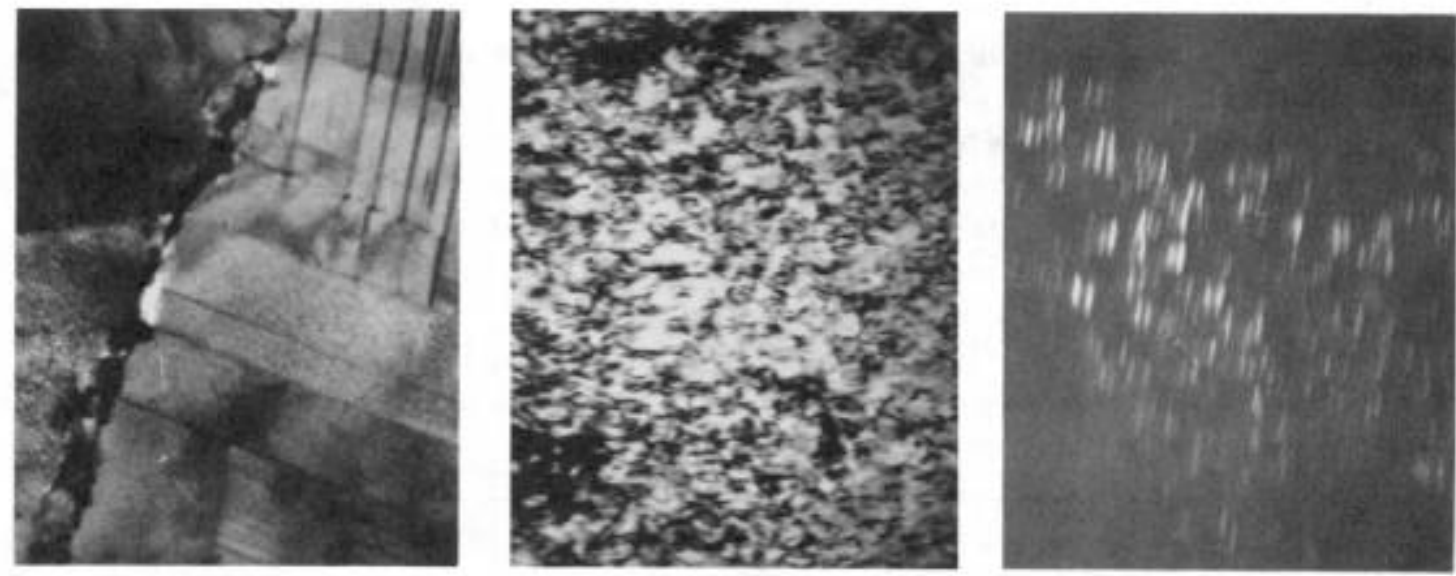

Figure 7. Transmission electronmicrographs of Alloy 5 after rupture in 394 hours at $650^{\circ} \mathrm{C}$ and $683 \mathrm{MPa}(99.5 \mathrm{ksi})$.

(a) Bright field, X10000. (b) Bright field, $\mathbf{X} 80000$.

(c) Dark field, X80000.
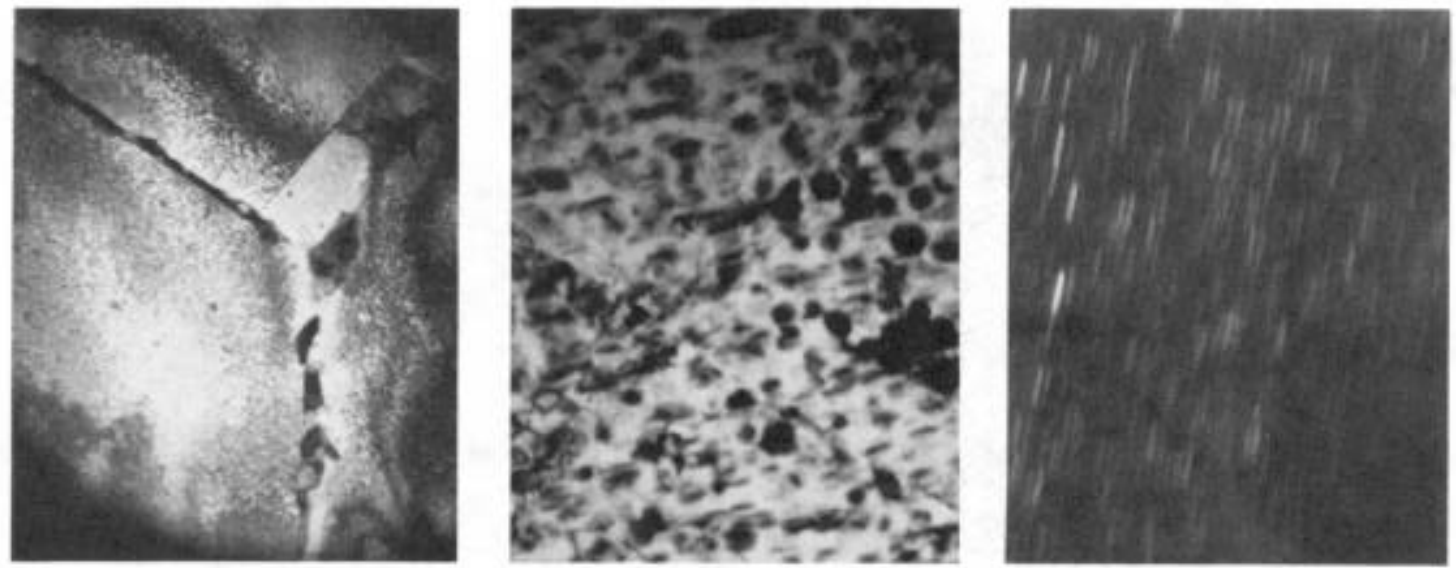

Figure 8. Transmission electronmicrographs of Alloy 5 after rupture in 63.4 hours at $730^{\circ} \mathrm{C}$ and $483 \mathrm{MPa}$ (70 ksi).

(a) Bright field, X10000. (b) Bright field, X80000.

(c) Dark field, X115000. 

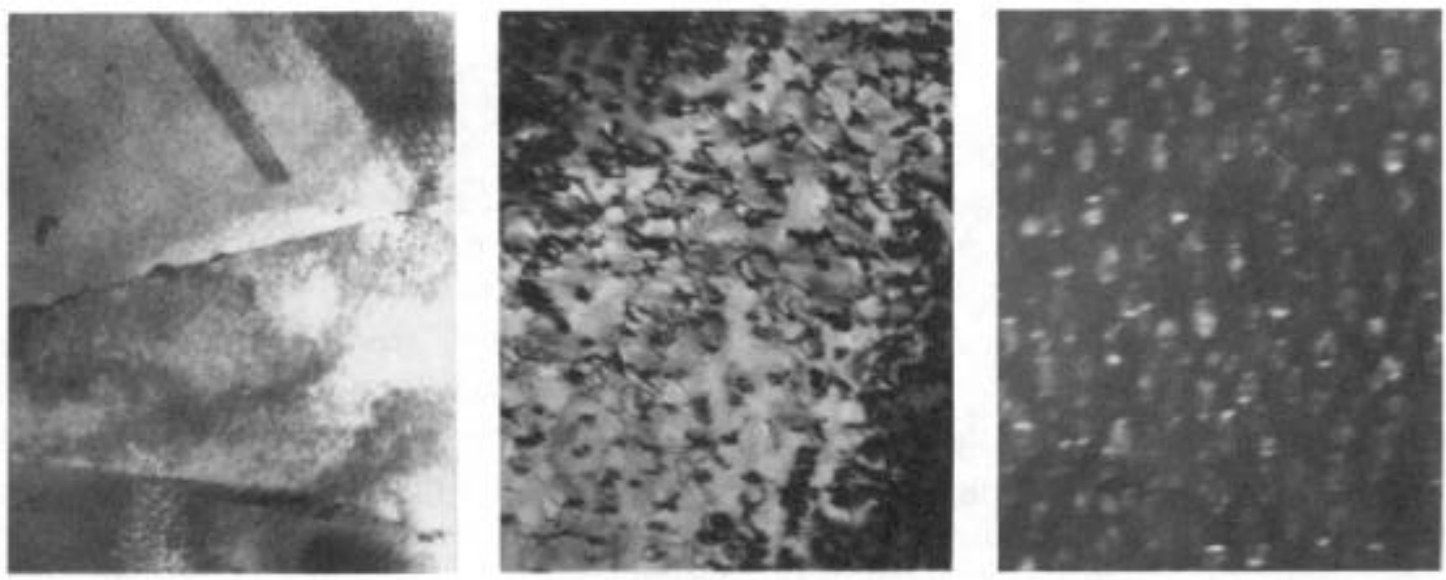

Figure 9. Transmission electronmicrographs of Alloy 7 after rupture in 22.9 hours at $730^{\circ} \mathrm{C}$ and $483 \mathrm{MPa}$ (70 ksi).

(a) Bright field, X]7000. (b) Bright field, X60000.

(c) Dark field, X60000.

under a stress of $686 \mathrm{MPa}(99.5 \mathrm{ksi})$. A tendency for $\gamma^{\prime \prime}$ phase growth was seen in some areas but with no change in other areas. Aside from the $\mathrm{M}_{6} \mathrm{C}$ phase, there was no $\delta$ phase in the grain boundaries and none was seen within the grains. The microstructure of Alloy 5 after surviving 63.6 hours at $730^{\circ} \mathrm{C}$ under $483 \mathrm{MPa}(70$ $\mathrm{ksi}$ ), per Figure 8, revealed slight tendency of $\gamma^{\prime \prime}$ growth but the form and amount of $\mathrm{M}_{6} \mathrm{C}$ in the grain boundaries did not change and there was no $\delta$ phase nywhere. The microstructure of Alloy 7 after 22.9 hours at $730^{\circ} \mathrm{C}$ under $483 \mathrm{MPa}$ (70 ks1) is shown in Figure 9. The compact ${ }^{\prime} / / \gamma^{\prime \prime}$ precipitate showed no growth (coarsening) tendency. A small amount of $\delta$ phase was observed in the grain boundaries but there was no $\delta$ phase within the grains.

In these comparisons between Alloy 5 and Alloy 7, the improvement in rupture life of Alloy 5 can be attributed to the observed differences in the respective $\gamma^{\prime} / \gamma^{\prime \prime}$ precipitates plus the effect of the tungsten addition in strengthening both the $\gamma$ matrix and the $\gamma^{\prime}+\gamma^{\prime \prime}$ phases. In addition, the formation of a small chain-like $\mathrm{M}_{6} \mathrm{C}$ precipitate in Alloy 5 strengthened the grain boundaries and therely contributed to the improvement in rupture life. These structural factors are controlled by the precipitate chemistry via optimum alloying additions (and appropriate heat treatment). The second factor to enhance high temperature properties is a high precipitate content. In this respect, the higher amount of the primary strengthening $\gamma^{\prime \prime}$ phase in Alloy 5, the smaller size of the $\gamma^{\prime}$ precipitate, and the higher volume fraction of $\gamma^{\prime \prime}$ from the extraction data, as well as $\mathrm{Nb}$ percentage relative to total hardening element content are the contributing factors.

\section{Discussion}

The goal of our research has been to extend not only the service range to higher temperatures but also to improve properties at the present ceiling temperature of about $650^{\circ} \mathrm{C}$ for conventional 718. This upper limit has been related to microstructural instability caused by the formation of the brittle and 
crack-like $\delta$ phase, and the accompanying dissolution of the precipitation strengthening metastable $\gamma^{\prime \prime}$ phase. Noteworthy is the higher tensile strength averaging $105 \mathrm{MPa}(2.2 \mathrm{ksi})$ between 400 and $700^{\circ} \mathrm{C}$ and the almost three times longer stress rupture life of Alloy 5 compared to Alloy 718 at $650^{\circ} \mathrm{C}$ under a stress of $686 \mathrm{MPa}(99.5 \mathrm{ksi})$. In age hardenable alloys, the heat treatment parameters determine mechanical properties and ultimately maximum service temperature. For the specified heat treatment, the mechanical properties of Alloy 5 were apparently optimized by the size and spacing of the $\gamma^{\prime} / \gamma^{\prime \prime}$ precipitates being more effective in impeding the motion of dislocations through the lattice. When the comparison is made with the cuboidal $\gamma^{\prime} / \gamma^{\prime \prime}$ morphology in Alloys 7 and 3, the coarsening rate of the $\gamma^{\prime \prime}$ phase growing in contact with the $\gamma^{\prime}$ precipitate and apart from it must have been lower. Although actual measurements are needed, it appears that the size and spacing of the precipitates in Alloy 5 provide maximum strengthening. In the initial study, ${ }^{1}$ employing the standard 718 heat treatment, Alloy 5 had the shortest $\gamma^{\prime \prime}$ length and less wt.pct $\delta$ phase after 534 hours at $730^{\circ} \mathrm{C}$ of the five modified 718 alloys.

Tensile properties after long time service are more important than hardness because turbine disk burst (the designer's primary concern) is by overspeed wherein the ultimate strength is approached by the average tangential stress. ${ }^{7}$ Ductile failure occurs when the average tangential stress reaches a large fraction of the ultimate stress; tests show values below 0.9. The higher tensile strength of Alloy 5 compared to Alloy 718 (as well as Alloys 3 and 7) over the 20 to $730^{\circ} \mathrm{C}$ range is noteworthy, and it should be ascertained if these properties are maintained after long time exposure in the 650 to $730^{\circ} \mathrm{C}$ range. Pertinent, in this regard, is the prior result on Alloy 5, when given the standard 718 heat treatment, which showed no reduction but rather higher tensile strength after 534 hours at $730^{\circ} \mathrm{C}(1420 \mathrm{MPa})$. The study by Barker et al. ${ }^{8}$ of twenty years ago provides a comparison based on a criteria of tensile properties after thermal exposure. They concluded that Alloy 718 will not have large losses in strength until there is significant overaging of the $\gamma^{\prime}$ and $\gamma^{\prime \prime}$ precipitates and formation of large quantities of $\delta$ phase. This did not occur in $200 \mathrm{hr}$ at $700^{\circ} \mathrm{C}\left(1300^{\circ} \mathrm{F}\right)$ but did occur in $800 \mathrm{hr}$ at $700^{\circ} \mathrm{C}$.

The introductory paper 4 showed the conversion of the data on our five modified alloys, when given the standard 718 heat treatment, to $100 \mathrm{hr}$ life via the Larson-Miller parameter and compared to the trend-line established for today's high-quality 718. The addition of the present data on Alloys 3,5 and 7 to the prior data on Alloys 3 and 5 produced the composite diagram, Figure 10. In the high stress range, it is evident that Alloy 5 has a $100 \mathrm{hr}$ rupture life at 25 to $40^{\circ} \mathrm{F}$ higher temperature than Alloy 718 whether the standard 718 or the modified heat treatment is employed. Although there are more data for the modified heat treatments than for the standard 718 heat treatment, it appears that there is no apparent difference between them and the precipitate structure in which only part of the $\gamma^{\prime \prime}$ is bound to the $\gamma^{\prime}$ particles in Alloy 5 provides superior results. Surprisingly, the compact $\gamma^{\prime} / \gamma^{\prime \prime}$ precipitate morphology in Alloy 7 provides, at best, equivalent results to conventional 718 but, more often, inferior results throughout the stress range. And these results were also confirmed when Alloy 3 was given the modified heat treatment which provided essential the same compact $\gamma^{\prime} / \gamma^{\prime \prime}$ structure.

The subject alloys represent three ways that the composition of Alloy 718 can be modified to provide higher $(\mathrm{Al}+\mathrm{Ti}) / \mathrm{Nb}$ and $\mathrm{Al} / \mathrm{Ti}$ ratios with higher 


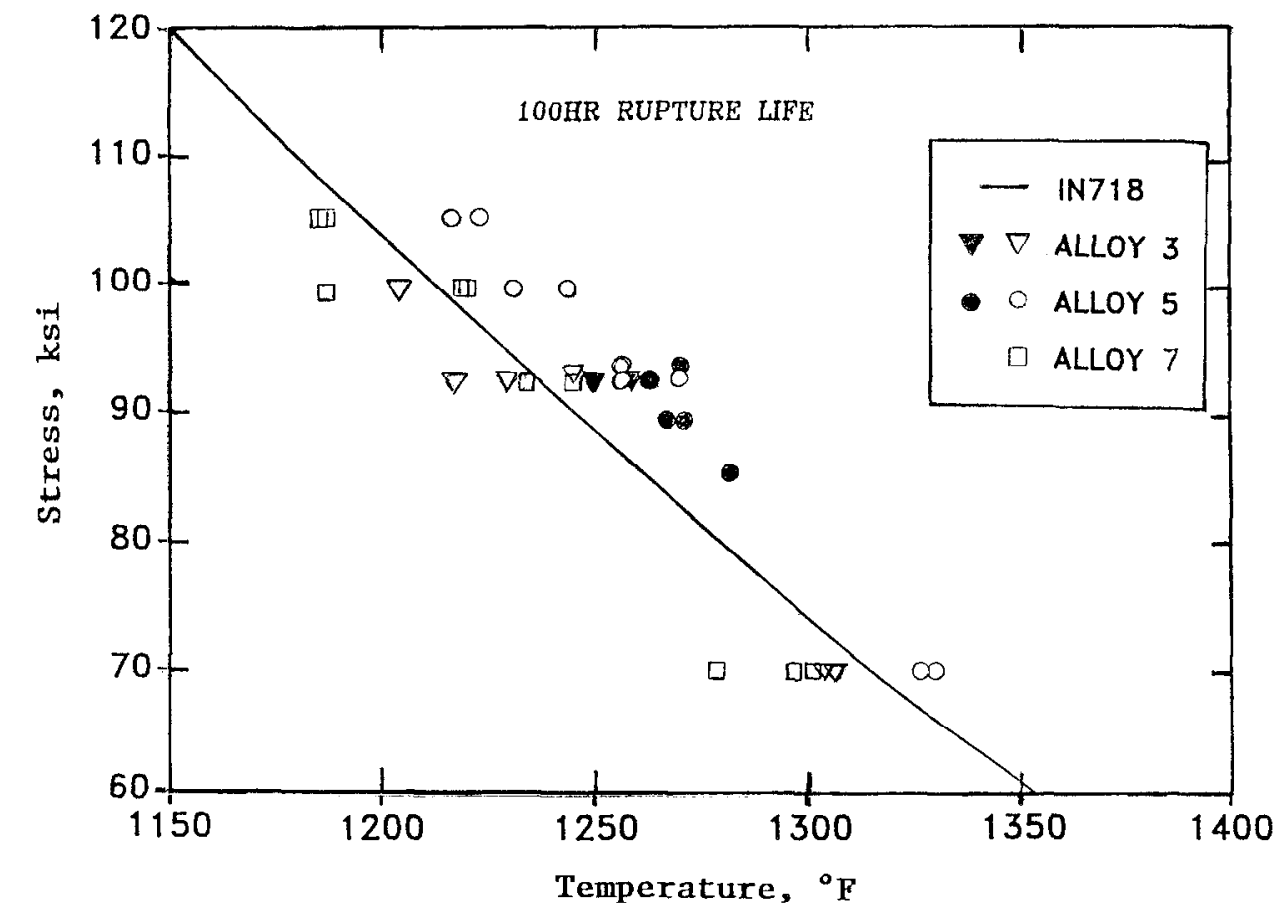

Figure 10. Conversion of stress rupture data for Alloys 3, 5 and 7 to 100 hour rupture life via the Larson-Miller parameter $(C=22)$ compared to trend-line established for today's quality Alloy 718 .

$(\mathrm{Al}+\mathrm{Ti}+\mathrm{Nb})$ total hardener content. Although Alloy 7 possessed the highest values in each case, Alloy 5 provided better thermal stability at and above $650^{\circ} \mathrm{C}$. In the manipulation of these elements, this result reveals that the correct balance of these elements is necessary in order to attain the optimum $\gamma^{\prime} / \gamma^{\prime \prime}$ precipitate structure from a particular heat treatment. In this comparison, Alloy 5 had a higher $\mathrm{Nb}$ percentage with respect to total hardener element content which would provide a higher $\mathrm{Nb}$ percentage in the $\gamma^{\prime \prime}$ precipitate which would be expected to increase the coherency strains. As a consequence, higher alloy strength was attained with satisfactory rupture life, indicative of phase stability. Also, it should be recognized that Alloy 5 contained a $W$ addition which would change the disposition of refractory elements in each phase, thereby modifying lattice mismatches between $\gamma / \gamma^{\prime}, \gamma^{\prime} / \gamma^{\prime \prime}$ and $\gamma / \gamma^{\prime \prime}$. Finally, it should be acknowledged that our results pertain to bar stock processed from small VIM heats rather than the commercial VIM-VAR plus TMP for disk production which could provide an improvement. Non-uniform dispersion of the precipitate phases would be detrimental to mechanical properties but the fact that all of the results are closely similar would negate this possibility.

\section{Conclusions}

Superior mechanical propertics wcre obtained with a non-compact $\gamma^{\prime} / \gamma^{\prime \prime}$ precipitate produced by a specified heat treatment in a modified Alloy 718 compared to two other compositional modifications having a cube-shaped, compact $\gamma^{\prime} / \gamma^{\prime \prime}$ precipitate with appropriate heat treatment. Higher tensile, impact 
and stress rupture properties were measured up to $730^{\circ} \mathrm{C}$, as well as in comparisons with conventional 718. The structural factors were controlled by the precipitate chemistry via optimum alloying additions and appropriate heat

treatment. There was an increase in the primary strengthening $\gamma^{\prime \prime}$ phase and the $\gamma^{\prime}$ particles were smaller in this alloy. Both the matrix and the $\gamma^{\prime}+\gamma^{\prime \prime}$ phases were strengthened by a tungsten addition. Also, the grain boundary was strengthened by a small chain of $\mathrm{M}_{6} \mathrm{C}$ phase which inhibited long range grain boundary sliding during stress rupture testing.

\section{References}

1. E. Guo, F. Xu and E.A. Loria, Superalloy 718: Metallurgy and Applications, TMS (1989), pp. 567-576.

2. E.A. Loria, High Temperature Materials for Power Engineering 1990, CRM Liege, Kluwer Academic Publishers (1990), pp. 1367-1375.

3. J.K. Tien, J.P. Collier, P.L. Bretz and B.C. Hendrix, High Temperature Materials for Power Engineering 1990, CRM Liege, Kluwer Academic Publishers (1990), pp. 1341-1356.

4. E. Guo, F. Xu and E.A. Loria, Preceding paper in this volume.

5. E. Andrieu, R. Cozar and A. Pineau, Superalloy 718: Metallurgy and Applications, TMS (1989), pp. 241-256.

6. J. Xie, Paper in this volume.

7. H.E. Miller and W.L. Chambers, Superalloys II, Wiley-Interscience (1987), pp. $27-58$.

8. J.F. Barker, E.W. Ross and J.F. Radavich, Journal of Metals (Jan. 1970), pp. 3141. 